EXTENDED REPORT

\title{
The direct brow lift: efficacy, complications, and patient satisfaction
}

\author{
A J Booth, A Murray, A G Tyers
}

Br J Ophthalmol 2004;88:688-691. doi: 10.1136/bjo.2003.019232

See end of article for authors' affiliations

a thors' affiliations

Correspondence to: Mr A G Tyers, Salisbury District Hospital, Salisbury SP2 8BJ, Wilts, UK. tonytyers@ compuserve.com

Accepted for publication 28 May 2003
Background/aims: The direct brow lift operation can be used to treat brow ptosis arising from either involutional changes or facial nerve palsy. The authors reviewed their experience with this operation to establish its efficacy and complication rate in the light of concerns over poor scar cosmesis and forehead paraesthesiae in the postoperative period.

Methods: A retrospective review of patients undergoing direct brow lifting from 1989 to 2002 was conducted, and information gained on patient satisfaction by questionnaire.

Results: The direct brow lift operation was found to give a predictable outcome, with high levels of patient satisfaction. With careful wound closure, postoperative scars are rarely cosmetically unacceptable to the patient. Paraesthesiae are a common but well tolerated sequelae.

Conclusions: The direct brow lift was found to be a reliable method for treating brow ptosis arising through involutional change or facial nerve palsy in both men and women. The postoperative scars may be more evident in younger patients so the authors reserve this technique for "rehabilitative" rather than cosmetic brow lifts in patients of middle age and beyond.
S urgical procedures to lift the ptotic brow were published in 1926 by Hunt ${ }^{1}$ and in 1930 Passot described the direct brow lift, involving excision of an ellipse of tissue immediately above the brow. ${ }^{2}$ This technique was subsequently modified to utilise a mid-forehead or a coronal incision. For some surgeons, however, these methods have been largely superseded by the endoscopic technique of brow lifting described by Vasconez in $1992 .{ }^{3}$

The direct brow lift is a simple procedure which allows the surgeon good control over the amount of tissue excised, and therefore the degree of lift achieved, as well as the postoperative contour of the brow. Nevertheless, the resulting scar may result in poor cosmesis, and damage to the supraorbital nerve may lead to paraesthesiae or numbness over the forehead region.

\section{AIMS AND METHODS}

We reviewed our experience with the direct brow lift operation in the light of ongoing concerns regarding unacceptable scar formation and peroperative nerve damage. We aimed to establish whether the direct brow lift still has a place and, if so, which patients are most suited to this technique.

The operative technique ${ }^{4}$ is as follows: mark the full length of the superior border of the brow adjacent to the uppermost brow hairs. Pull the brow up to its intended postoperative height and hold the marker pen at this point. With the pen held steady above the forehead skin allow the brow to drop back to its ptotic position and mark the forehead skin at the level of the pen. Repeat this manoeuvre at several sites along the brow to outline the amount of skin, subcutaneous tissue, and muscle to be resected. Join the line of these marks to the original mark to form an ellipse.

Identify the position of the supraorbital nerve and vessels. Make an incision along the marked ellipse and deepen it, keeping at right angles to the skin. At the medial end of the ellipse stay within the subcutaneous fat layer to protect the supraorbital nerve and vessels. In the lateral half of the ellipse deepen the incision just deep to the fat layer, exposing the frontalis muscle. In patients with facial palsy deepen this lateral part of the incision to the loose areolar tissue superficial to the periosteum. Excise the ellipse of tissue with constant attention to preservation of the supraorbital nerve and vessels.

Close the wound in two layers. Use a 4/0 monofilament absorbable suture-for example, Monocryl, to the close the deep layers. The suture should close the fat layer and pass through the dermis immediately deep to the epidermis and the knot should be placed deeply. In facial palsy the deep suture may also be passed through the periosteum to help fix the position of the brow.

Close the skin with a subcuticular 4/0 monofilament suture. Place Steri-strip dressings along the wound and tape the ends of the skin closure suture under a further layer of Steri-strips. Remove the skin suture and Steri-strips at 5-7 days.

We performed a retrospective review of all direct brow lifts performed by, or under the supervision of, one oculoplastic surgeon (AGT) from 1989 to 2002 with a minimum follow up of 3 months.

Information was gathered from the patient case notes concerning patient demographics, aetiology, and severity of brow ptosis; presence of associated dermatochalasis; details of previous surgery; complications arising; and outcome of surgery. A questionnaire to determine patient satisfaction with the procedure was devised and sent out with an explanatory letter to the patients in this group. The responses to the three questions were recorded on a simple five point "smiley face" visual analogue scale.

\section{RESULTS}

In all, 54 direct brow lift operations were performed on 36 patients identified from the departmental database. This group of patients consisted of 17 men and 19 women with an average age of 69 (range 47-83). The aetiology of the brow ptosis was seventh cranial nerve palsy in 17 patients, and involutional in the other 19 patients (see fig 1).

The preoperative degree of brow ptosis was assessed subjectively as being mild ( $1-2 \mathrm{~mm}$ ) in eight cases, moderate $(3-4 \mathrm{~mm})$ in 21 , and marked $(>4 \mathrm{~mm})$ in 23 . In the remaining two cases no comment concerning severity was 


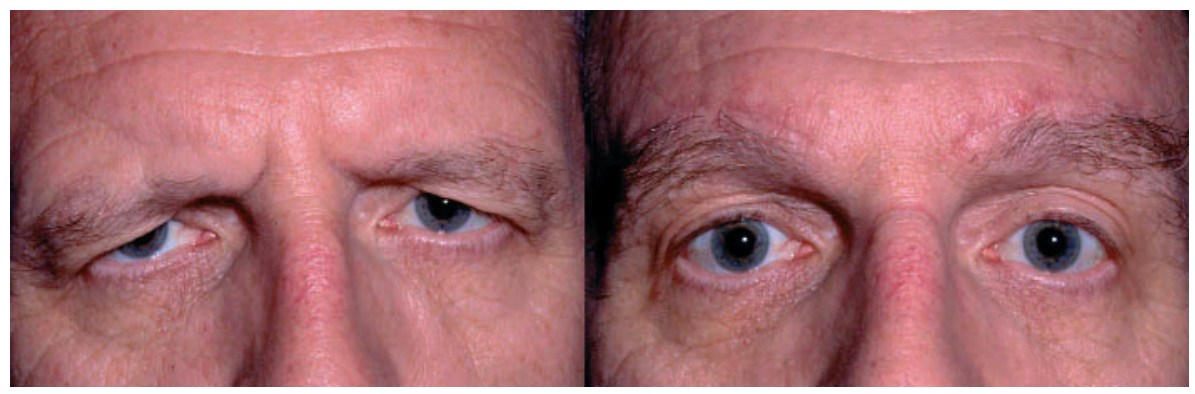

Figure 1 (Left) Involutional brow ptosis. (Right) Three months after direct brow lifts. (Reproduced with permission of the patient.)

recorded. Fourteen of the cases had undergone previous lid or brow surgery, mostly in relation to the management of facial palsy (lateral tarsorrhaphy, medial canthal tendon plication, medial canthoplasty, and lateral canthal sling). Two patients (three brows) had undergone blepharoplasty before the brow lift, and one had undergone a previous direct brow lift following facial nerve palsy. Dermatochalasis was found in addition to brow ptosis in 36 of the 54 cases, and 15 of these underwent a subsequent blepharoplasty.

All patients underwent direct brow lifting between 19892002, using the technique outlined above. The mean follow up period was 11 months (range 3-44). The outcome of surgery was documented as being good or satisfactory in 52 cases, one of which was initially slightly high, but eventually obtained final symmetry. In the two remaining cases, both of whom were in patients having unilateral surgery for seventh nerve palsy, the brow was left too low leading to slight asymmetry. One of these was the patient who had previously had brow lift surgery.

Paraesthesiae and numbness were the most frequently documented complications, occurring in 22 cases. Prominence of the surgical scar was noted in two patients (four brows) postoperatively. Although this prominence diminished over the following 2 months, both patients remained unhappy with the scar cosmesis according to their questionnaire responses. There was one postoperative wound infection and one case of suture abscess, which resolved with a course of antibiotics.

The questionnaire of patient satisfaction consisted of three questions. Question 3 was to be answered only if numbness or tingling over the forehead was still present.

- Q1 How satisfied are you with the cosmetic appearance of the scar above your eyebrow?

- Q2 How satisfied are you with the amount that the eyebrow has been lifted?

- Q3 How much are you bothered by numbness or tingling over your forehead?

The responses to questions 1 and 2 were graded in five steps (very happy, happy, neutral, unhappy, and very unhappy) using a standard "smiley face" visual analogue scale. The responses to question 3 were graded in five steps from "not at all" to "a great deal," also using the same visual analogue scale.
A total of 34 questionnaires were sent out (three patients were known to have died) and a reply was received from 28 (concerning 43 brows). Four further questionnaires were returned stating that two patients had since died, and two had moved away with no forwarding address.

The patients were either happy or very happy with the scar cosmesis in 35 of the 43 cases, neutral in four, and unhappy in a further four cases. As mentioned, this latter group consisted of two patients who were noted to have prominent scars postoperatively

A happy or very happy response was gained in 32 of the 43 cases in relation to satisfaction with the degree of lift gained, with five neutral and six unhappy responses. There were no clues as to the reasons for the latter group's dissatisfaction as a favourable surgical outcome had initially been documented in all these cases.

There were 11 brows unaffected by paraesthesiae or numbness. Of the remaining 32, 14 were not at all bothered by it, and 15 were only slightly troubled. Only three brows were still affected by significant problems. The two patients concerned had undergone surgery in January and August 2001.

The questionnaire responses are summarised in table 1.

\section{DISCUSSION}

The ideal brow position has been a matter of some debate among cosmetic and oculoplastic surgeons alike, as discussed in a paper by Gunter and Antrobus. ${ }^{5}$ Nevertheless, a simple concept of the ideal brow position was described by Westmore in $1974 .{ }^{6}$ This stated that the medial brow should begin on the same vertical plane as the lateral extent of the nasal ala and the inner canthus, and that it should end laterally at an oblique line from the most lateral point of the nasal ala and the outer canthus. The medial and lateral ends of the brow should be at approximately the same horizontal level, and the apex of the brow curve should lie directly above the lateral limbus. The medial end of the ideal brow is club shaped and it gradually tapers laterally. These anatomical associations were echoed by Ellenbogen, who also added that in women the brow should arch to above the supraorbital rim, whereas in men it should arch along the rim.

McKinney et al state that the minimum distance from midpupil to the top of the brow should be $2.5 \mathrm{~cm} .{ }^{8}$ If this distance is shorter brow ptosis exists. Clinically, brow ptosis may be said to be present if the brow has dropped partially or wholly

\begin{tabular}{|c|c|c|c|c|c|}
\hline & Very unhappy & Unhappy & Neutral & Happy & Very happy \\
\hline $\begin{array}{l}\text { Q1 (cosmetic appearance) } \\
(n=43)\end{array}$ & 0 & 4 & 4 & 12 & 23 \\
\hline Q2 (amount of lift) $(n=43)$ & $\begin{array}{l}0 \\
\text { "a great deal" }\end{array}$ & 6 & $\begin{array}{l}5 \\
\text { "a bit" }\end{array}$ & 7 & $\begin{array}{l}25 \\
\text { "not at all" }\end{array}$ \\
\hline $\begin{array}{l}\text { Q3 (numbness/tingling) } \\
\text { ( } \mathrm{n}=32 \text { ) }\end{array}$ & 2 & 1 & 10 & 5 & 14 \\
\hline
\end{tabular}


below the supraorbital rim, and may arise either through a combination of involutional changes in the facial tissues and gravity or following damage to the facial nerve.

Excessive skin in the upper eyelid may be wholly or partially attributable to ptosis of the eyebrows. In such cases performing a blepharoplasty alone may inadequately correct the dermatochalasis. More seriously, it may produce further lowering of the eyebrow leading to an unacceptable cosmetic result. It is therefore important that significant brow ptosis is corrected before proceeding with surgery for any residual dermatochalasis.

Several surgical options are available for correcting brow ptosis including trans-blepharoplasty browpexy, direct brow lift, mid-forehead lift, coronal brow lift, and endoscopic brow lift.

\section{Trans-blepharoplasty browpexy}

The trans-blepharoplasty brow lift achieves brow elevation or fixation through a standard blepharoplasty incision. The lateral eyelid is debulked by excising the descended lateral galeal and preseptal fat pad, and the brow is anchored with mattress sutures to the periosteum above the supraorbital rim. Additionally, the procerus and corrugator muscles may be approached through the same incision if required. This procedure has the advantages of simplicity, and placement of the wound within a naturally occurring skin crease. Disadvantages include the limited amount of brow lift which can be achieved, and damage to the supraorbital neurovascular bundle if the medial portion of the brow is approached. Dissection into the lateral fat pads inevitably causes damage to branches of the lacrimal, zygomaticofrontal, and zygomaticotemporal nerves. In a report describing this surgical technique, McCord and Doxanas state that the resulting anaesthesia and paraesthesia of the lateral brow is transient and sensation returns within 6 months. ${ }^{9}$

\section{Direct brow lifting}

Direct brow lifting, as described in this study, has been typically reserved for those patients who have no desire for a coronal brow lift, or in whom the scars of a coronal lift would be unacceptable-for instance, in male pattern baldness or a high hairline. The main advantage is that it gives the greatest degree of lift per mm of tissue excised and gives the surgeon better control over the brow position and contour. The main criticism of this technique is the postoperative scar which may be unsightly, or may become sunken or hypertrophic. Furthermore, postoperative paraesthesiae and anaesthesia may occur over the forehead region because of damage to the corresponding sensory nerves. Nevertheless, very few of the published series of direct brow lifting have quantified the incidence of these complications or have looked into patient satisfaction following the procedure. This is also true of series involving other techniques of brow lifting.

In their review of brow lifting procedures, Green et al suggest that, with careful layered wound closure as described in our technique, the postoperative scars are rarely a problem. ${ }^{10}$ They point out that these scars may be further camouflaged by the use of cosmetics and spectacle wear. They also describe bringing the dissection plane of the ellipse of forehead tissue more superficially towards its medial end to avoid damage to the supraorbital nerve and blood vessels. Other authors, including Johnson et $a l^{11}$ and Jarchow, ${ }^{12}$ have reported low complication rates following direct brow lifting. No exact quantification is presented however. Ueda et al reviewed 40 patients, who underwent a direct brow lift for facial nerve palsy, with a minimum follow up time of 3 years. ${ }^{13}$ They reported a $27.5 \%$ incidence of postoperative paraesthesiae but did not state whether this was a transient or permanent phenomenon. They also found high levels of patient satisfaction with the cosmesis of the postoperative scar with $77.5 \%$ reporting "hardly any dissatisfaction," and no patient completely dissatisfied. In our study we found similarly high levels of satisfaction with the cosmesis of the scar, with $81 \%$ (35/43 brows) being either happy or very happy with the outcome. From the results of our patient survey, we found a higher incidence of altered sensation over the forehead at $74 \%$ (32/43 brows), but in only $7 \%(3 / 43$ brows) were the patients unhappy or very unhappy about this. Reports of the efficacy of direct brow lifting are rare, and more often than not are based on the surgeon's perspective of success rather than the patient's. We found a high level of satisfaction with the degree of lift achieved, with 74\% (32/43 brows) giving either a "happy" or "very happy" response to the questionnaire. It is interesting to note, however, that in six cases an "unhappy" response was given despite a favourable outcome being recorded in the notes.

Our questionnaire was not intended to be a formal test of quality of life, and these results should not be interpreted as such. Nevertheless, we think that the use of simple questions and an easy to interpret visual analogue scale gives a fair indication of the patient's perception of the outcome of surgery, as distinct from the surgeon's. It should also be emphasised that the group of patients included in this study were offered direct brow lifting primarily for reasons of comfort and visual rehabilitation rather than cosmesis.

\section{Mid-forehead lift}

The mid-forehead lift utilises a forehead crease as the foundation of the incisions. Rafaty et $a l^{14}$ and Brennan ${ }^{15}$ have recommended this technique in preference to the direct brow lift as they think that scars immediately above the brow are cosmetically unacceptable and are not amenable to camouflage with make-up in a man. This technique can be used to good effect especially in men who have deeper forehead creases and receding hairlines. The potential disadvantages are the same as for a direct lift, in terms of scarring and altered sensation. Rafaty et al state minimal complications and cosmetically acceptable scars with this method, but no quantifiable data are given.

\section{Coronal brow lift}

This technique utilises either a pre-trichial or post-trichial incision, and has the advantage of allowing correction of glabellar frown lines and forehead rhytids while lifting the brow. The procedure is therefore not appropriate for those patients with a high hairline or those with thinning hair. Furthermore, there are numerous potential complications following this procedure including sensory and motor nerve dysfunction, skin necrosis, permanent overcorrection, alopecia, abnormal soft tissue contour, and eyebrow and eyelid asymmetry. Fett et al report a series of 22 patients who had undergone this procedure, all of whom developed tightness, constriction, and itching lasting several weeks. ${ }^{16}$ However, as pointed out by Withey et al, no in-depth studies of the complication rates of this operation exist. ${ }^{17}$

\section{Endoscopic techniques}

Endoscopic methods of brow lifting were described by Vasconez et al in $1992^{3}$ and Isse in1994, ${ }^{18}$ and have been reported by Steinsapir et $a l^{19}$ and Holck $^{20}$ (among others) to have comparable success rates to open coronal lifting, but a significantly lower incidence of complications and a faster rehabilitation time. Nevertheless, neither of these studies provides quantifiable data. A study by Withey et $a l^{17}$ of 100 patients who underwent endoscopic brow lifting found postoperative numbness in 57/80 cases and itching in 37/80 cases. Other commonly occurring complications were hair loss (19/80), tissue swelling (18/80), and asymmetry (9/80). 
Despite this, levels of patient satisfaction were high, with $84 \%$ of patients stating that they would undergo the procedure again. Other disadvantages of this technique include an inherent learning curve in the procedure and the additional expense of the equipment needed. In addition, the surgery itself is more time consuming than with alternative methods.

\section{SUMMARY AND CONCLUSIONS}

All of the above techniques of brow lifting have their own potential advantages but none is without risk of complication. Furthermore, as demonstrated by Freund and Nolan, brow lifting by any method may fail to achieve the "ideal" aesthetic brow position. ${ }^{21}$ Nevertheless, we have shown that the direct brow lift operation, as described above, gives a reliable and predictable outcome, with high levels of patient satisfaction. It is a simple, quick procedure which requires no specialised equipment and does not require extensive training to perform. By adhering to careful dissection techniques which avoid the supraorbital neurovascular bundle, and meticulous layered closure of the wound, postoperative dissatisfaction related to altered forehead sensation and poor scar cosmesis can be minimised. We have therefore found this technique to be suitable for patients of both sexes, with brow ptosis arising through either involutional changes or facial nerve palsy. The youngest patient in this series was 47 . The scars may be more evident in younger patients so we reserve this technique for "rehabilitative" rather than cosmetic brow lifts in patients of middle age and beyond.

\section{Authors' affiliations}

A J Booth, A Murray, A G Tyers, Salisbury District Hospital, Salisbury SP2 8BJ, Wilts, UK

\section{REFERENCES}

1 Hunt HL. Plastic surgery of the head, face and neck. Philadelphia: Lea and Febinger, 1926.

2 Passot R. Chirurgie esthetique pure: techniques et results. Paris: Gaston Doin et $\mathrm{Cie}, 1930$.

3 Vasconez LO. The use of an endoscope in brow lifting. A video presentation at the Annual Meeting of the American Society of Plastic and Reconstructive Surgeons. Washington DC, 1992.

4 Tyers AG, Collin JRO. In: Colour atlas of ophthalmic plastic surgery. 2nd ed. Oxford: Butterworth-Heinemann, 1997:178-82.

5 Gunter JP, Antrobus SD. Aesthetic analysis of the eyebrows. Plast Reconstr Surg 1997;99:1808-16.

6 Westmore MG. Facial cosmetics in conjunction with surgery. Course presented at the Aesthetic Plastic Surgical Society Meeting, Vancouver, British Columbia, 1975.

7 Ellenbogen R. Transcoronal eyebrow lift with concomitant upper blepharoplasty. Plast Reconstruct Surg 1983;71:490-9.

8 McKinney P, Mossie RD, Zukowski ML. Criteria for the forehead lift. Aesthetic Plast Surg 1991;15:141.

9 McCord CD, Doxanas MT. Browplasty and browpexy: an adjunct to blepharoplasty. Plast Reconstruct Surg 1990;86:248-54.

10 Green JP, Goldberg RA, Shorr N. Eyebrow ptosis. Int Ophthalmol Clin 1997;37:97-122.

11 Johnson JM, Anderson JR, Katz RB. The brow lift 1978. Arch Otolaryngol 1979; 105:124-6.

12 Jarchow RC. Direct browplasty. South Med J 1987;80:597-600.

13 Ueda K, Harii K, Yamada A. Long term follow up study of browlift for treatment of facial paralysis. Ann Plast Surg 1994;32:166-70.

14 Rafaty FM, Goode RL, Abramson NR. The brow lift operation in a man. Arch Otolaryngol 1978;104:69-71.

15 Brennan HG. Correction of the ptotic brow. Otolaryngol Clin N Am 1980;13:265-73.

16 Fett DR, Sutcliffe RT, Baylis HI. The coronal brow lift. Am J Ophthalmol 1983;96:751-4.

17 Withey S, Witherow $\mathrm{H}$, Waterhouse N. One hundred cases of endoscopic brow lift. Br J Plast Surg 2002;55:20-4.

18 Isse NG. Endoscopic facial rejuvenation: endoforehead, the functional lift. Case reports. Aesthetic Plast Surg 1994;18:21.

19 Steinsapir KD, Shorr N, Hoenig J, et al. The endoscopic forehead liff. Ophthalmic Plast Reconstruct Surg 1998;14:107-18.

20 Holck DEE, Ng JD, Wiseman JB, et al. The endoscopic browlift for forehead rejuvenation. Sem Ophthalmol 1998;13:149-57.

21 Freund RM, Nolan WB. Correlation between brow lift outcomes and aesthetic ideals for eyebrow height and shape in females. Plast Reconstruct Surg 1996;97:1343-8. 